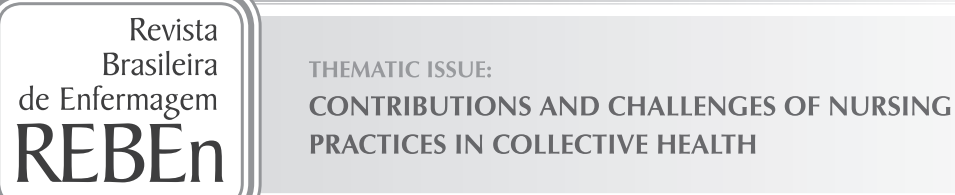

\title{
The complexity of the work of nurses in Primary Health Care
}

\author{
A complexidade do trabalho do enfermeiro na Atenção Primária à Saúde \\ La complejidad del trabajo del enfermero en la Atención Primaria a la Salud
}

\section{Sandra Rejane Soares Ferreira', Lisiane Andréia Devinar Périco', Vilma Regina Freitas Gonçalves Dias" \\ ' Hospital Nossa Senhora da Conceição, Community Health Management. Porto Alegre, Rio Grande do Sul, Brazil. "Qualirede Consultoria Empresarial. Florianópolis, Santa Catarina, Brazil.}

\begin{abstract}
How to cite this article:
Ferreira SRS, Périco LAD, Dias VRGF. The complexity of the work of nurses in Primary Health Care. Rev Bras Enferm [Internet]. 2018;71(Supl 1):784-9. [Issue Edition: Contributions and challenges of practices in collective health nursing] DOI: http://dx.doi.org/10.1590/0034-7167-2017-0471
\end{abstract}

\begin{abstract}
Objective: to promote thinking on the work of nurses in Primary Health Care (PHC) and the necessary aspects for the (re)construction of this professional practice, reinforcing its role in the care of individuals, families and communities. Method: to apply the questions raised in the process of organizing a book, the literature and the PHS work experience of the authors. Results: Conflicts, dilemmas and relevant aspects of the practice of nurses in PHC are presented, contributing to critical thinking about the context of work and the need to articulate the category in the construction of its workspace. Final considerations: the practice of nurses in PHC is broad and a process of qualification field, whether performing in clinical, educational or managerial activities, and nurses need to be familiar with these contents in their daily work, seeking to articulate their class entities for the development of this specialty.
\end{abstract}

Descriptors: Community Health Nursing; Primary Care Nursing; Family Health Nurses; Advanced Nursing Practice; Access to Health Services.

\section{RESUMO}

Objetivo: promover reflexão sobre o trabalho do enfermeiro na Atenção Primária à Saúde (APS) e sobre os aspectos necessários para a (re)construção dessa prática profissional, consolidando esse espaço de atuação no cuidado das pessoas, famílias e comunidades. Método: as questões apontadas para a reflexão foram construídas no processo de organização de um livro, baseadas na literatura e na experiência de trabalho na APS das autoras. Resultados: apresentam-se conflitos, dilemas e aspectos relevantes da prática do enfermeiro na APS, contribuindo com o pensamento crítico sobre o contexto de trabalho e a necessidade de articulação da categoria na construção do seu espaço profissional. Considerações finais: a atuação do enfermeiro na APS é um campo amplo e em processo de qualificação, seja na prática clínica, educativa ou gerencial e os enfermeiros precisam se apropriar desses conteúdos no seu cotidiano, buscando a articulação com suas entidades de classe para o desenvolvimento dessa especialidade.

Descritores: Enfermagem em Saúde Comunitária; Enfermagem de Atenção Primária; Enfermeiras de Saúde da Família; Prática Avançada de Enfermagem; Acesso aos Serviços de Saúde.

\section{RESUMEN}

Objetivo: promover reflexión sobre el trabajo del enfermero en la Atención Primaria a la Salud (APS) y sobre los aspectos necesarios para la (re)construcción de esa práctica profesional, consolidando ese espacio de actuación en el cuidado de las personas, familias y comunidades. Método: las cuestiones apuntadas para la reflexión fueron construidas en el proceso de organización de un libro, basadas en la literatura y la experiencia de trabajo en la APS de las autoras. Resultados: se presentan conflictos, dilemas y aspectos relevantes de la práctica del enfermero en la APS, contribuyendo con el pensamiento crítico sobre el contexto de trabajo y la necesidad de articulación de la categoría en la construcción de su espacio profesional. Consideraciones finales: la actuación del enfermero en la APS es un campo amplio y en proceso de calificación, ya sea en la 
práctica clínica, educativa o gerencial y los enfermeros necesitan apropiarse de esos contenidos en su cotidiano, buscando la articulación con sus entidades de clase para el desarrollo de esa especialidad.

Descriptores: Enfermería en Salud Comunitaria; Enfermería de Atención Primaria; Enfermeras de Salud de la Familia; Práctica Avanzada de Enfermería; Acceso a los Servicios de Salud.

\section{CORRESPONDING AUTHOR_Sandra Rejane Soares FerreiraＥ-mail: sandrarsfer@gmail.com}

\section{INTRODUCTION}

Nursing is a socially relevant professional practice, historically determined and part of a collective working process to promote health initiatives through a specific knowledge, articulated with the other members of the team in the social political context of the health sector.

Primary Health Care (PHC) is the first level of care and is characterized by a set of actions in the individual and collective scope, which include health promotion and protection, disease prevention, diagnosis, treatment, rehabilitation and maintenance of health ${ }^{(1)}$. We highlight that the Brazilian Ministry of Health $(\mathrm{MH})$ in the Ordinance approving the National Primary Health Care Policy (NPHC) $)^{(1)}$ considers equivalent the terms "Primary Care (PC)", "Family Health Strategy (FHS)" and "Primary Health Care (PHC)", used in Brazil. In this paper we chose to use the $\mathrm{PHC}$ terminology.

The role of nurses in PHC in Brazil is being constituted as an instrument for changes in health care practices in the SUS [Brazilian Unified Health System], responding to the proposal of the new care model that is not centered on clinical and healing, but above all, comprehensive care, intervention in relation to risk factors, prevention of diseases and promotion of health and quality of life.

According to Matumoto ${ }^{(2)}$, the practice of nurses in the Brazilian PHC is understood as a social practice, that is, one based on the social health needs that occur at a historical moment; it is constituted and becomes the dynamic of relations with other social practices that compose the SUS scenario.

This article aims to promote reflection on the practices of nurses in PHC, how they have been occurring and what is considered necessary for the (re)construction of professional practices capable of consolidating this space of action in an increasingly effective way in the care of people, families and communities.

The questions raised for the reflection are the result of a project carried out in the years 2015/2016, by a group of nurses, who organized the book "Nursing Practice in PHC" aiming at the construction of a theoretical and practical reference for the nurses who work in this area, based on the authors' and collaborators' study of nursing literature and experience of more than 20 years in the PHC.

It is intended to present some issues identified as relevant in the practice of nurses in the PHC, to promote reflection among colleagues and nursing class entities about this field of action, which are:

1. What are the roles of nurses in PHC in Brazil?

2. How is the practice of nurses in PHC occurring?

3. What kind of professional is the nurse who works in the $\mathrm{PHC}$ ?

4. How to support and qualify nurses practice in PHC?

\section{WHAT ARE THE ROLES OF NURSES IN PRIMARY HEALTH CARE IN BRAZIL?}

In addition to the common attributions for all professionals in the PHC team, the specific nurse assignments defined in the $\mathrm{NPHC}{ }^{(1)}$ include actions directed at individuals, families and the community, in order to guarantee full assistance in the promotion and protection of health, prevention of diseases, diagnosis, treatment, rehabilitation and maintenance of health, in the different social spaces and in all phases of the life cycle. These are: a) to perform health care for the individuals and families registered in the teams and, when indicated or needed, in the domicile and/or other community spaces (schools, associations, etc.) in all stages of human development, such as: childhood, adolescence, adulthood and elderly; b) to conduct procedures; c) to carry out activities in groups; d) to carry out nursing consults, request complementary examinations, prescribe medications, observing the legal provisions of the profession and the protocols or other technical regulations established by the Ministry of Health, the state, municipal or Federal District managers and, when necessary, users to other services; e) to carry out programmed activities and attention to spontaneous demand; $\mathrm{f}$ ) to plan, manage and evaluate the actions developed by the Community Health Agents ( $\mathrm{CHA}$ ) together with the other members of the team; g) to contribute, participate, and carry out ongoing education activities of the nursing team and other team members; and h) to participate in the management of necessary inputs for the proper functioning of the Primary Healthcare Unit (PHU) $)^{(1)}$.

To perform this diversity of actions (common and specific) that competes to them, nurses need to develop several competences, which undergraduate and specializations courses of the area manage to fulfill. Therefore, it is essential that the services develop Permanent Education Programs. Among the range of activities developed in the PHC by this professional, nursing consultation is considered one of the most relevant, but studies $^{(2-5)}$ indicate that nurses cannot always perform it fully.

According to Matumoto ${ }^{(2)}$ and Nauderer ${ }^{(5)}$, the work of nurses in PHC is based on two dimensions: a) promotion of care and management of the therapeutic process; b) management activities of the health service and the nursing team.

The practices of nurses in PHC have been developed according to the legal requirements of the practice of this profession, especially the nursing consultation. In a study carried out by Matumoto(2), the nurses considered as a direct clinical activity the following: a) user embracement, b) nursing consultation (related to pap smear, prenatal and puerperium examination, family planning, childcare, hypertensive and diabetic, mental health), c) home visit/home care, d) work in groups. As indirect clinical activities, they defined: a) supervision and 
guidance to nursing assistants; b) supervision and guidance of the $\mathrm{CHA}$; and c) actions to support the physician's care ${ }^{(2)}$.

The nursing work in the PHC has a dual dimension, which are care and management, focused on the individual (production of nursing care and management of therapeutic projects) and on the collective (monitoring of the health situation of the population, management of the nursing team and the health service for the promotion of care) and its essential function is to provide assistance to people, families and communities, developing activities to promote, maintain and recover health, thus contributing to the implementation and consolidation of $\mathrm{SUS}^{(3,5)}$.

Bomfim $^{(3)}$ carried out a study in which the intervention of nurses in the PHC were mapped according to the Nursing Interventions Classification (NIC), in 152 activities, distributed in 7 domains, 16 classes and 59 interventions. The only activity that did not correspond to the interventions proposed by the NIC was the user embracement. The activities identified in the study corroborate the description of a diverse daily practice of nurses in $\mathrm{PHC}$, being considered in all domains proposed by the $\mathrm{NIC}^{(3)}$. The International Classification of Nursing Practice in Collective Health (CIPESC) project in Brazil lists 105 nursing activities carried out in the PHC, which were also mapped by Chianca $^{(6)}$, according to the NIC. The two studies found a relevant percentage of activities in the Health System and Community domain (54\% and 62\%). It is possible to observe that in both studies there is a concentration of activities in health service management and nursing team to the detriment of promoting care and managing the therapeutic process. The nurse is performing activities in the domains that are predominantly those that support the effective use of the health care system $^{(3,6)}$.

\section{HOW IS THE PRACTICE OF NURSES OCCURRING IN PRIMARY HEALTH CARE?}

The daily life of the PHC nurse in SUS is marked by the conflict of being responsible for the set of activities that make up the health service's working dynamics and the specific work advocated by the new care model, within a context where the strategies of management and ideological aspects that reinforce the traditional model of health system functioning ${ }^{(7)}$. In this context, nurses have their activities increasingly directed to procedures linked to the organization of the service, to the supervision of the activities carried out by the $\mathrm{CHA}$ and to the care provided by the members of the nursing team ${ }^{(7-8)}$.

One of the crucial features of daily life, highlighted in some studies $^{(4,7-9)}$, is the work overload due to the accumulation of several functions and the removal of nurses from direct care (especially the nursing consultation), which arise from the need to provide answers to the demands related to the functioning of the health services and the population, as well as the established goals, pacts and indicators of the health service ${ }^{(7)}$. The prioritization of demands that require more urgent responses in the daily life related to managerial issues leaves nurses distant from the direct assistance, reality and health needs of the population ${ }^{(7)}$. The charge imposed on nurses is not proportional to the conditions they are given to respond with quality to the prerogatives of family health and to meet spontaneous demand ${ }^{(7,9)}$. Thus, we observe the existence of conflicting situations in decision-making processes, since they recognize that some activities will be neglected, which normally are their general attributions, so that another one is carried out, causing feelings of frustration and doubt as to their performance in $\mathrm{PHC}^{(4,7,9)}$.

The nurses in PHC have been gaining social space and recognition among the members of the health team and the users who experience clinical care with them and identify the reference for care in it, bringing great satisfaction and providing meaning to work $^{(2)}$. In their work, nurses recognize the potentials for performing clinical practice through nursing consultation, creating links with the population and establishing interpersonal relationships with the team that provide a productive, healthy and satisfactory work environment ${ }^{(7)}$. Four aspects were highlighted by FHS nurses as important for the accomplishment of their attributions, they are: a) appreciation and recognition; b) permanent education; c) established link with the community; and d) working together with the $\mathrm{CHA}^{(7)}$.

The International Council of Nurses (ICN) states that, nurses have been developing their role in an innovative way in the world and proposes to carry out studies about the activities role internationally known as "Advanced Nursing Practices"(10). Drug prescription be one of these innovations of the profession and has been implemented since the early 1990s in a number of countries and contexts, especially those with a well-established health and nursing system in PHC with advanced practices and functions well defined for nurses. Among these countries, Sweden, Australia, Canada, United States, United Kingdom and New Zealand were identified as the first to implement this experience, followed by South Africa, Botswana, Ireland and Kenya ${ }^{(10)}$.

In Brazil, the Professional Nursing Practice Law [Lei do Exercício Profissional da Enfermagem] (No. 7.498./86) and its regulatory decree (No. 94.406/87) guarantee nurses in the nursing consultation the right to prescribe drugs approved by institutional protocols. Moreover, the Ordinance No. 2.488/11 (NPHC) establishes that "it is up to the nurse to perform nursing consultations, to request complementary examinations and to prescribe medications, observing the legal provisions of the profession and according to the protocols or other technical regulations established by the Ministry of Health"(1).

Regarding the difficulties and limitations of the practice of nurses in PHC in Brazil, the following issues were pointed out in the literature $(2-5,7,9)$.

- Lack of human resources of different areas; lack of materials and equipment generating overload to the workers and repercussion in the whole of the work process and in the satisfaction of the user with the offered service;

- Lack of human resources for support actions in the health unit such as reception and withdrawal of medical records, support to local management, among others, hampering the organization and agile operation of the service;

- Insufficient number of nursing professionals in the health unit lead nurses to cover the basic nursing work that supports all other team work to the detriment of the execution of their specific assignments such as: nursing consultation, considered a core action in the PHC; 
- Work overload with administrative, managerial and support activities for the health service, the organization of spontaneous demand and the infrastructure limiting the clinical practice of nurses in PHC;

- Lack of recognition of clinical work in the organization and management of services;

- No understanding and patience of users to nurses when they cannot solve the identified problems, requiring referrals to a fragile and disjointed network;

- Extensive territorial area of the health unit making it difficult for both the user and the worker to access home visits;

- Precarious employment link, leading to a high turnover of professionals, which generates work overload for those who remain with weak work processes, commitment of the bond with the population served and the quality of the assistance, as well as spending time and energy training new professionals;

- Disparities in structural conditions in different health units for clinical practice, lack of a properly equipped and exclusively nurses' office;

- Lack of qualification for the nursing consultation in the several areas of the scope of the PHC to guarantee the quality in the assistance provided;

- Inexistence of technical support and supervision for the clinical practice of nursing; and

- The protocols of the Ministry of Health, although officially adopted by the Municipal Health Secretariats, do not always meet the needs of nursing professionals because they fail to properly describe the duties of nurses in policies to be implemented.

\section{WHAT TYPE OF PROFESSIONAL IS THE NURSE OF PRI- MARY HEALTH CARE?}

In all work functions two types of professional profiles predominate: generalists and specialists. Generalists are capable of interacting with various areas of knowledge because they develop a wide view of phenomena, valuing all dimensions of knowledge. They have the capacity to relate various elements involving people, available resources, social contexts and technical competences. They have a broad view of everything surrounding them, but the extent of their field of action imposes limits on the depth of specific knowledge. On the other hand, specialists are dedicated to the in-depth study of an area being considered expert in it.

PHC is a very broad field and nurses must master several skills to perform their work effectively, such as: management of their work process, clinical and abstract reasoning, planning, communication, time management, scientific health of the child, women's health, contagious diseases, gestation, immunization, mental health, skin lesions, hypertension, diabetes, among many others. Considering the size and diversity of this area, the important question is: in how many areas would the nurse be able to know the subject with the adequate depth for a PHC specialist to perform effective and quality work for people, families and the community?

When we think of specialists, we need to think about all the skills that are related to each specialty. In this sense, will our Residency Programs and Specialization Courses be able to train family health specialists?

Relating the range of activities that are responsibility of nurses who work in the APS, we reflect on the profile and the need for this professional, considered generalist, to be at the same time a specialist in interacting with the various areas to make decision. Would the PHC nurse be a highly qualified "Generalist" with a practical vision in the choice and application of behavior or technology?

We can consider them multipurpose professionals, capable of acting in several areas, specialists in the intervention of the most frequent health problems/needs in PHC services. But what is the price of being so versatile for your professional satisfaction and for the quality of care you provide to people, families, and the community?

Would a specialty be possible combining the two types of professional profiles for better performance with the health teams, considering that clinical practice is renewed every day and requires permanent updates?

A generalist view is essential for a position of coordinating a team so that decisions are made assertively. For example, when coordinating and supervising the work of the nursing team and $\mathrm{CHA}$, nurses need to know all the actions that are performed by the Health Unit. However, to evaluate a skin lesion and define the type of coverage to be applied, specific knowledge of this area is required.

The need to vary between these two positions, for which they do not always have technical knowledge and skills to deal with, causes nurses tensions and anxiety, since they need to practice according to the new model of attention in their practice. It is often found a space of disputes including health workers, users and managers ${ }^{(2,8)}$. In addition, the nonspecific demands that arise in the day-to-day worsen the daily tensions of nurses when they need to transit in an unknown territory that waits for invention of new ways to face the health problems and that depend on the integrated work with others members of the team ${ }^{(2,7)}$. This picture of tensions, complexity and "non-knowledge" is faced in different ways by nurses. Some are willing to build this practice while others are $\operatorname{not}^{(2)}$.

\section{HOW TO SUPPORT AND QUALIFY THE PRACTICE OF NURSES IN PRIMARY HEALTH CARE?}

The analysis of the daily practice in our service, the data of the various studies on the practice of nurses in PHC, and the factors that favor and hinder the work, make it possible to deduce that in some respects nurses perceive satisfaction in their work and see a broad field of action to be built, but they do not yet know the direction to strive for, in the sense of (re) constructing the practices within the new assistance model recommended by the SUS, but still implemented in a fragile way. Therefore, it is considered necessary:

- To continue the studies that aim at the identification and validation of nursing interventions in $\mathrm{PHC}$, which would constitute the first step towards the construction of an instrument to identify the time spent in these 
interventions, making it possible to know the actual nursing workload and consequently, contribute to a more efficient planning of human resources in this area;

- To study the attributions of the nurse in the PHC to specify them with regard to the dimensions of care and management, given that it implies assuming different roles;

- To expand studies that focus on the identification of individual and collective strategies against the adversities found in the process of work of nurses in PHC;

- To promote the construction of a professional career with the current assignments divided into specialties according to the two major areas of nursing practice in PHC: a) promoting care and managing the therapeutic process (this could be further subdivided into large areas of activity such as maternal and child health, chronic diseases, home care, health surveillance and contagious infectious diseases, among others); and b) managing health services;

- To provide technical support and infrastructure (municipal and state management) with an incentive to prioritize clinical practice to consolidate this field of action. It is necessary that nurses understand this process of social construction, because it depends on them to gain their space and consolidate their practices ${ }^{(2,7)}$;

- To implement Permanent Education Programs focused on nursing consultation with technical support and supervision of clinical practice. These spaces should promote a critical reflection on one's own doing, articulating practice with reflection and new knowledge (the practice itself and thinking about it) - building a cyclical movement in the environment of work, making possible the overcoming of states of alienation caused by immersion in overloaded working state ${ }^{(2,5)}$;

- To implement specific, clear, structured protocols based on the competencies and attributions of the nurse to provide technical-scientific knowledge (know-how); consider the epidemiological reality of the region, the health needs of the local population, professional autonomy, qualification assistance and technical and legal support;

- To promote capacities for the use of light technologies that can support the complexity of PHC practices, among them: extended clinical practice (listening, welcoming, bonding, accountability), case management, the Clinical Protocols, the organization of Care Lines, networking, as well as skills to deal with the high degrees of uncertainty intrinsic to this work ${ }^{(2)}$;
- To promote an initiative together with the class entities to (re)think the work process in order to strengthen the clinical practice before the people, families and community and seek propitiate resolutive care in the face of the needs of SUS users.

In relation to the workload of nurses with administrative, managerial and support activities in the health service, the organization of spontaneous demand and the infrastructure, there is an immediate need for a shared process management among all the staff so that the clinical work of this professional is not imprisoned by activities that, in their essence, do not contemplate their main object of intervention ${ }^{(2,5,9)}$ or compose the $\mathrm{PHC}$ team with a larger number of nurses so that they can effectively carry out these services work in these two dimensions (care and management).

\section{FINAL CONSIDERATIONS}

The review of literature and the practical experience of the nurses authors of this reflection allow us to consider that the practice of nurses in PHC is a very broad and qualifying field, whether performing in clinical activities, health education, or managerial role.

Nurses in PHC can extend their autonomy through a clinical practice sustained from the perspective of integrality and care to families and communities throughout their life cycle. It is necessary to organize the nurses who work in the PHC to structure and strengthen a professional career proposal, contributing to the consolidation of changes in the SUS health care model.

We hope that the aspects brought in this article of reflection may contribute to the debate of the category and class entities on the expansion of the work scope of the PHC nurse in the Brazilian reality. Consolidating the work of the $\mathrm{PHC}$ nurse through well-established professional careers with defined roles can be a way to obtain greater professional satisfaction and to overcome the dilemmas of daily practice as to be "generalists vs. specialists" nurses or to be professionals "who care vs. who manage". Thus, nurses who choose to act in the dimension of "production of care and management of the therapeutic process" will be able to devote a greater time to this activity and to provide full care to the user in a more qualified way, accompanying them throughout the life cycle with prevention, promotion, treatment and rehabilitation, providing meaning to the relationship of health services with individuals in the community, as well as contributing to universal coverage and access to $\mathrm{PHC}$.

\section{REFERENCES}

1. Brasil. Ministério da Saúde. Portaria no 2.488, de 21 de outubro de 2011. Aprova a Política Nacional de Atenção Básica, estabelecendo a revisão de diretrizes e normas para a organização da Atenção Básica, para a Estratégia Saúde da Família (ESF) e o Programa de Agentes Comunitários de Saúde (PACS). [Internet]. 2011[cited 2017 Jun 10]. Available from: http://bvsms.saude. gov.br/bvs/saudelegis/gm/2011/prt2488_21_10_2011.html

2. Matumoto S, Fortuna CM, Kawata LS, Mishima SM, Pereira MJB. Nurses' clinical practice in primary care: a process under construction. Rev Latino-Am Enfermagem [Internet]. 2011[cited 2017 Jun 01];19(1):123-30. Available from: http://dx.doi. org/10.1590/S0104-11692011000100017 
3. Bonfim D, Gaidzinski RR, Santos FM, Gonçales CS, Fugulin FMT. The identification of nursing interventions in primary health care: a parameter for personnel staffing. Rev Esc Enferm USP [Internet]. 2012 [cited 2017 Jun 01];46(6):1462-70. Available from: http://dx.doi.org/10.1590/S0080-62342012000600025

4. Assis WD, Collet N, Reichert APS, Sá LD. Work process of the nurse who works in child care in family health units. Rev Bras Enferm[Internet]. 2011[cited 2017 Jun 01];64(1):38-46. Available from: http://dx.doi.org/10.1590/S0034-71672011000100006

5. Nauderer TM, Lima MADS. Nurses' practices at health basic units in a city in the south of Brazil. Rev Latino-Am Enfermagem [Internet]. 2008[cited 2017 Jun 01];16(5):889-94. Available from: http://dx.doi.org/10.1590/S0104-11692008000500015

6. Chianca TCM, Souza CC, Werli A, Hamze FL, Ercole FF. The nursing interventions used at clinical practice in Brasil. Rev Eletr Enf[Internet]. 2009[cited 2017 Jun 01];11(3):477-83. Available from: http://www.fen.ufg.br/revista/v11/n3/v11n3a03.htm

7. Caçador BS, Brito MJM, Moreira DA, Rezende LC, Vilela GS. Being a nurse in the family health strategy programme: challenges and possibilities. Rev Min Enferm [Internet]. 2015[cited 2017 Jun 01];19(3):612-26. Available from: http://www.reme.org.br/ artigo/detalhes/1027

8. Galavote HS, Zandonade E, Garcia ACP, Freitas PSS, Seidl H, Contarato PC, et al. The nurse's work in primary health care. EsC Anna Nery Rev Enferm[Internet]. 2016[cited 2017 Jun 01];20(1):90-8. Available from: http://www.scielo.br/pdf/ean/v20n1/14148145-ean-20-01-0090.pdf

9. Baratieri T, Marcon SS. Longitudinality of care in nurses' practice: identifying the difficulties and perspectives of change. Texto Contexto Enferm[Internet]. 2012[cited 2017 Jun 01];21(3):549-57. Available from: http://www.scielo.br/pdf/tce/v21n3/v21n3a09

10. Ball J, Barker G, Buchan J. Implementing Nurse Prescribing: an updated review of current practice internationally. International Council of Nurses, Genéve, 2009. 94 p 